\title{
Piaget and Parables: The Convergence of Secular and Scriptural Views of Learning
}

\author{
JAMES D. FOSTER and GLENN T. MORAN \\ George Fox College \\ New'berg, Oregon
}

Jean Piaget is widely acclaimed as a developmental theorist who has contributed much to the understanding of how children learn. While many educators adhere to Piaget's model of learning, few realize that techniques similar in structure were used by Jesus 2000 years ago. Basic components of Piaget's theory, namely assimilation, accommodation, and disequilibration of the learner, are evidenced in the parabolic method used by Jesus. This comparison between Piaget's theory and Christ's parabolic method suggests that an effective teacher would cognitively activate and disequilibrate the learner. Insights from Scripture and Piaget's theory imply that motivation through disequilibration should be effective with students having a variety of experiences, a wide spectrum of abilities, and a mixture of learning styles.

Jean Piaget's developmental theory has been widely influential in psychology and education over the past two decades. This theory views cognitive growth during the lifespan as an epigenetic progression through increasingly complex stages. This article will attempt to integrate psychological theory and theology by showing that key Piagetian concepts such as assimilation, accommodation and disequilibration, were central to Christ's teaching methods and were exemplified in his use of the parabolic method. Approximately one third of Christ's teaching in the first three gospels is in parables (Stein, 1981), and according to Morgan (1943), the parabolic method becomes the preferred method when resistance to Jesus' ministry de velops (e.g. Mark

Requests for reprints should be sent to James D. Foster, PhD, Department of Psychology, George Fox College, Newberg, Oregon 97132.
2:18; Mark 2:23-24; Mark 3:22). While other authors have examined parables as change agents (Grauf-Grounds, 1982; Shepperson, 1981), their relationship to Piagetian theory has been overlooked. The structure of parables, their similarities to Piagetian theory, and educational insights from the parabolic method are the foci of this article.

\section{Piaget's Learning Theory}

Piaget sees cognitive development proceeding through four qualitatively distinct stages (Flavell, 1963). Beginning with the sensorimotor stage, a person progresses through preoperational and concrete operational stages to the highest level of cognition at the stage of formal operations. Each stage builds on the previous stage and results in increasingly sophisticated thought. Progression from stage to stage is accomplished through the complementary processes of assimilation and accommodation. 
Assimilation can be defined as the integration of new perceptions of stimulus events into existing mental structures called schemes. Accommodation is defined as creating a new scheme or modifying an old one in response to new information. Accommodation occurs when new material cannot be fitted into existing schemes or when the person's understanding is best served by the creation of two or more schemes where there once was one. Overriding these continuous processes is an innate homeostatic type of mechanism which attempts to maintain cognitive equilibrium. While assimilation, accommodation, and equilibration are an integral part of understanding how the person progresses through the cognitive stages to the highest level, that of formal operational thinking, it also appears that these processes continue even after reaching the highest stage.

Assimilation and the other related processes that make up Piaget's approach to learning begin to operate at birth, if not before. The fact that learning takes place prenatally has been demonstrated experimentally. When a loud sound is made near a pregnant mother's abdomen, the fetus typically responds with a large change in fetal heart rate. Subsequent repetitions of the noise will not elicit the same response indicating adaptation and hence learning (Sontag \& Newberry, 1940). Similarly, Spelt (1948) has demonstrated that the 28 -week-old fetus can be classically conditioned. These studies suggest that the Aristotelian/Lockian concept of "blank slate" has no place in developmental psychology and that at no time during a lifetime does one actually learn something "new." Piaget (1970) writes, "Indeed, no behavior, even if it is new to the individual, constitutes an absolute beginning. It is always grafted onto previous schemes and therefore amounts to assimilating new elements to already constructed structures." (p. 707). No child then, is born free of some learning and at any point in the lifespan the person uses existing schemes to deal with new material. A teacher lecturing to a class, as well as a parent explaining to a child, makes a fundamental error if they assume no understanding precedes their explanation. The person being bombarded with new information fits what is being heard into existing schemes; this is assimilation. There is no other way of dealing with what is being presented except to impose the available structure onto the new information. A good example of a person struggling to fit the unfamiliar into available cognitive structures can be found in the book of Revelation where John attempts to understand visions of a future at least 2000 years away. John's assimilation results in a heavy usage of the word "like" as he fits the barely comprehensible new information into his existing schemes (e.g. Revelation 4:1; 4:3; 9:7-10;11:1;13:2;14:2).

John's conceptual struggle illustrates another important aspect of assimilation: change. Inherent in assimilation is modification; new information is modified by the listener to fit into existing schemes. Teachers face this daily as the carefully prepared, lucid lecture is immediately manhandled into the student's schemes whether they are primitive or sophisticated. The starting point for any new concept is always the existing mental structures the student possesses. Piaget (1968) writes "every structure has a genesis" and "genesis emanates from a structure and culminates in a structure'" (pp. 149, 147). The student modifies the concept being presented, fits it to existing structures and then understands, but this understanding is less than or different from that which was intended. This is an important point and should be remembered when dealing with students and in personal studies. It does not matter whether the material to be mastered is secular or divinely inspired. The fact is that we must understand new material through old, and often inadequate mental structures. This affects what is learned and how it is understood. Thorson (1981) states,

the important fact that a divine revelation is the real source of our knowledge does not eliminate the purely 


\section{J.D. FOSTER AND G.T. MORAN}

epistemological problems of communication, interpretation, and comprehension, nor does it impart a special status or rational certainty to our knowledge itself. We walk by faith: the truth is divine. but it is held by earthen vessels, human and fallible. (p. 132)

Without additional cognitive processes, an assimilating person would endlessly attempt to force new concepts into existing schemes. What processes then account for the creation of new schemes and cognitive development? Put simply, new schemes are created by scheme failure. When a child who refers to a butterfly as a bird is frequently corrected by his parents, the child experiences scheme failure. The previously broad understanding of "bird" must now be refined through accommodation. Teachers who wish to guide their students to a more sophisticated understanding must begin with existing schemes, activate these schemes and then create a situation where these older understandings become inadequate. A person who has experienced this scheme failure is disequilibrated: the cognitive equilibrium is upset, causing the person to seek a new understanding and, as such, a new equilibrium. One way to move a person to a new level of understanding, then, is through disequilibration.

\section{The Teacher's Dilemma}

Teachers must face several realities which affect the learning situation. First, the typical student will begin to learn by fitting new information into existing mental structures. Second, as this assimilation takes place omissions and distortions will occur to the extent that the existing conceptual framework is inadequate. These inadequacies in understanding will occur regardless of the clarity or cleverness of the presentation and should be accepted as a necessary step in the learning process. Third, students will become uneasy with their present understandings as they repeatedly experience failure and sense the inadequacy of their current way of thinking. Fourth, students will experience disequilibration as they realize that their understanding is less than adequate for the task at hand. This uncomfortable state of disequilibration creates a drive for new and better understanding. A disequilibrated person understands the problem at hand, the inadequacies of his way of thinking and will recognize a superior way of understanding. Finally, it has been emphasized that all learning begins at the student's existing cognitive level. It must also be recognized, however, that students in a given learning situation will all be at different levels of understanding. The wider the range of student experience, ability and understanding, the more difficult it will be for the teacher to accomplish educational goals. The people Jesus ministered to exemplified this diversity.

Jesus attempted to bring the "good news" to people who already possessed a traditional, well established, legalistic religion. $\mathrm{He}$ had to deal with the undereducated masses as well as the educated religious elite. In addition, his message was to be carried to the Gentiles who were not steeped in the long history and tradition of Judaism. Given this variety in culture, education, experience, and age of his audience, how did he go about maximizing understanding?

Although educators today seldom face groups as diverse as that which Christ faced, there are parallels. For example, a general psychology class will be largely made up of academically naive freshmen, more experienced sophomores, and a sprinkling of academically sophisticated juniors and seniors. A percentage of the freshmen will have had a high school course in psychology which will give them an advantage, unless of course it was a poor course, in which case they will be at a disadvantage. These students will also vary in the way they think and approach problems. These variations are called cognitive styles and have been described in many ways (e.g. field independence-dependence, conceptualizing styles, reflectiveness-impulsivity, and so forth; Kogan, 1971). Given this tremendous variety in experience, ability, interest and cognitive style that exists in a single class- 


\section{SECULAR AND SCRIPTURAL VIEWS OF LEARNING}

room, how does one teach? Finkel and Monk (1979) suggest that educational techniques based on Piagetian theory should work despite classroom diversity.

\section{A Piagetian Teaching Technique}

Working from a Piagetian perspective, Finkel and Monk (1979) begin with the assumption that in order to alter someone's thoughts, regardless of previous experience or ability, the person must be disequilibrated. They suggest that this can be done by presenting a series of problems that eventually cannot be solved with the student's present conceptions. Using a worksheet approach, groups of students are presented with a series of increasingly difficult problems. Good worksheets would meet the following criteria (Finkel \& Monk, 1979):

First the student must be made to see the problem as a genuine problem that requires resolution. Such a problem must be formulated from the student's own view of the phenomenon. . . . The problem itself only comes into consciousness as a result of questions that force upon the student the inadequacy of his or her present conceptions. . . . It must throw the student into a state of intellectual disequilibrium. Conflict between the student's differing conceptions or between obdurate phenomena and unsophisticated theories must make the student feel the problem in all of its perplexing force, and lead him or her to want to solve it. . . . It is not enough to perplex students and leave them hanging. Relevant information, guides, questions, and examples must be provided so that the students have a reasonable chance of making new distinctions and tying ideas together in a different way. (p. 36)

The three phases can be summarized as follows:

1. Activate the learner's schemes by presenting a common, easily understood problem.

2. Sequence tasks so that eventually a problem's resolution is beyond the current conceptions of the learner, resulting in disequilibration.

3. Provide guidance and information which allow reestablishment of equilibrium at a higher level of understanding.

\section{Jesus' Parabolic Method}

Using the Piagetian paradigm, it can be seen that an effective teaching technique must begin by activating the proper schemes of the listener. Examination of Scripture makes it clear that Jesus was using this technique in his ministry. For example, when studying the parables one is immediately struck by the simplicity of the settings. There are farmers sowing seed (Mark 4:220), people at weddings (Matthew 22:1-14; 25:1-13), workers in vineyards (Matthew 20:1-16) and shepherds tending sheep (Matthew 18:12-14). The listener must also have been familiar with the people and places used, such as priests, Levites, Samaritans, and the road from Jerusalem to Jericho. Clearly the listener could visualize the parables in a way that the typical reader today cannot. These settings appear to have been sufficiently familiar to activate the schemes of the listener regardless of class or educational level.

The second phase in Piaget's paradigm states that disequilibration of the learner is essential for enhanced understanding. It is only when a new experience interacts with the previously existing cognitive structure, that the structure is altered making it more adequate. While Jesus' stories were about typical life and behavior, they often contained atypical elements. For example, in Matthew 18:24, Jesus speaks of a servant who has been given 10,000 talents. To the casual reader this may not seem like a significant amount, but 10,000 talents was twenty times the yearly tribute of Galilee and Perea (Stein, 1981). This is an example of how the Master presented new experiences and thoughts to force the listener to disequilibrate and accommodate creating new cognitive structures concerning spiritual truths. As Stein (1981) states: "Jesus' parables caught their listeners by surprise because the behavior they expected stood in sharp contrast with the behavior portrayed in the parables" (p. 40). Examples of this include the commendation of the dishonest steward (Luke 16:1-8), the immoral behavior of the prodigal son and his ultimate forgiveness (Luke 15:11-32), the refusal of invitations to banquets and royal weddings 
(Luke 14:15-24; Matthew 22:1-4), and an employer who pays the same wage for one hour's work as for twelve (Matthew 20:116). The second phase of learning, then, is accomplished by including unusual events or moral dilemmas.

Jesus' use of unexpected behavior, moral dilemmas, and exaggerated responsibilities surely disequilibrated his listeners. Without the disruption of their current schemes, the radical new concepts he wished to teach, such as grace, forgiveness, and love of one's enemies, might have been rejected.

Everyday settings coupled with unusual elements parallel the Piagetian-based phases of activation and disequilibration. The third phase, guidance, is also accomplished through Jesus' teachings. Jesus did not seek to disrupt his listeners' existing moral standard without providing something to replace it. Through the explanations and admonitions which frequently accompanied his parables, and through lectures such as the Sermon on the Mount, rigid and legalistic beliefs were replaced by a new doctrine of love and forgiveness.

To this point it can be seen that the parabolic method clearly accomplishes the three key phases of learning according to Piagetian theory. However, several methods could have accomplished this same goal. Therefore, there must have been other reasons for using parables.

One possible explanation for Jesus' use of parables is given by Barclay (1970). He believes that Jesus used parables to reach the broader audience described earlier. According to Barclay, he was teaching two groups: Greeks, who were known for their abstract arguments, and Jews, who liked practical stories. In pointing out that the parable meets both of their needs, Barclay theorizes that "He knew what was in man; and He gave us these cameo-like pictures we call parables so that the great ideas He wished to teach might become comprehensible" (p. 12).

From a Piagetian perspective these picture-inducing stories served two pur- poses: first, to establish a common everyday setting which would activate the schemes of listeners regardless of age, background, and education; second, to deal with what must have been a largely concrete operational crowd. Learners at this level are able to use rules based on concrete instances but cannot deal with abstract qualities. Concrete operational thinkers can best solve problems if the problems can be visualized or if they have had previous experience with the elements of the problems. Jesus' use of familiar settings and events was clearly concrete.

While Barclay (1970) is not a psychologist, his suggestion that Jesus was dealing with an audience of diverse intellectual development is undoubtedly correct. Recent research suggests that while concrete operational thinking may be inevitable and universal, the higher level of formal thought is not (Keating \& Clark, 1980; Neimark, 1975). Cross cultural studies suggest the ability to reason from hypotheses (formal operational thought) is not a widespread ability. For example, studies in Turkey indicate that the appearance of formal thought is limited to the cities and is not widespread in the primitive villages (Kohlberg \& Gilligan, 1971). It appears that the presence of a formal educational system encouraging writing forces the person to separate thought from the concrete objects and encourages possibility thinking in place of actuality thinking (Cole, 1978; Greenfield \& Bruner; 1966).

While the culture at the time of Christ is not exactly comparable to modern Turkey, the lack of a widespread, formal educational system during Christ's time suggests a crowd of listeners characterized primarily by concrete operational thinkers. Indirect support for this assumption may come from examination of the elaborate structure of rules developed by the Jews and their rigid, legalistic enforcement. Such highly specific and rigid rules often characterize moral systems developed by concrete operational thinkers. Biehler (1978) describes one such experience:

One fifth grade teacher who asked his pupils to suggest 
class rules had to call a halt when the list reached sixty-with no end in sight. (One reason for the length of the list was that specific rather than general rules were suggested-for example, "Don't run in the hall," "Don't run in the classroom," "Don't run on the way to lunch," "Don't run on the way back from lunch.") (p. 122)

Given a crowd made up of primarily concrete operational thinkers, how does one convey a message with radical theological implications? Christ used parables which operated at several levels. First, as has been shown, parables served to activate the existing cognitive structures through simplicity and familiarity. Second, the parables provided practical, concrete stories of what to do and what not to do in given situations. Third, the parables presented his theological revolution in a manner that challenged even the formal operational priests. Indeed the abstract implications of Christ's message have been occupying the minds of great thinkers for thousands of years.

\section{Summary}

Examination and comparison of Scripture and teaching methods based on Piagetian theory suggests that Piaget's view of the learning process and Jesus' view, based on his use of parables, are very similar. We believe that the compatibility of these psychological and theological facts should give us confidence in the learning theory and teaching methods discussed in this article. We are not suggesting, however, that simply finding similar facts in psychology and theology makes them any truer. Farnsworth (1982) addressed this problem when he warned against lining up psychological and theological facts that agree only superficially. He then went further saying:

[An] example may be seen in the hypothetical proposition that a synthesis of Carl Rogers' unconditional positive regard concept and Jesus' very similar comment on love in Matthew 5:44 produces an idea that is truer than either idea alone. If something is true in the first place, however, it cannot become truer, even though one's confidence in it and commitment to it as truth can become stronger by finding the same truth in other disciplines. (p. 317)

The purpose, then, in examining the pedagogy of Jesus and modern learning theories for parallels, is to develop a teaching technique in which theorists can put their confidence, as Christians, psychologists, and educators.

In summary, the learning process outlined above, regardless of the learner's cognitive style, age, experience, sex, or whether the message is secular or divine, necessarily follows three steps. First, the existing schemes of the learner must be activated, second, the person must be disequilibrated through the failure of existing schemes, and third, a new understanding must be created. Christ's recognition of this process and the difficulty of dealing with diverse audiences can be seen through his widespread use of parables and through the structure of parables. It is suggested that effective teaching techniques will be those that recognize and work within the limitations of the audience and the structure of the learning process.

\section{REFERENCES}

Barclay, W. (1970). And Jesus said: A handbook on the parables. Philadelphia: Westminster Press.

Biehler, R. F. (1978). Psychology applied to teaching. (3rd ed.). Boston: Houghton Mifflin.

Cole, M. (1978). How education affects the mind. Human Nature, I(4), 50-58.

Farnsworth, K. E. (1982). The conduct of integration. Journal of Psychology and Theology, 10, 308-336.

Finkel, D. L. \& Monk, G. S. (1979). The design of intellectual experience. The Journal of Experiential Education, 2(2) 31-38.

Flavell, J.H. (1963). The developmental psychology of Jean Piaget. Princeton, NJ: Van Nostrand.

Grauf-Grounds, C. (1982). Language as change agent: Metaphor in the work of Jay Haley and in the parables of Jesus. Journal of Psychology and Theology, 10, 212-220.

Greenfield, P. J. \& Bruner, J. (1966). Culture and cognitive growth. International Journal of Psychology, $l$, 89-107.

Keating, M. C. \& Clark, L. V. (1980). Development of physical and social reasoning in adolescents. Developmental Psychology, 16, 23-30.

Kogan, N. (1971). Educational implications of cognitive styles. In G. S. Lesser (Ed.), Psychology and Educational Practice (pp. 242-292). Glenview, IL: Scott Foresman.

Kohlberg, L. \& Gilligan, C. (1971). The adolescent as a philosopher: The discovery of self in a postconventional world. Daedalus, 100, 1051-1086. 


\section{J.D. FOSTER AND G.T. MORAN}

Morgan, C. (1943). The parables and metaphors of our Lord. Westwood, NJ: Fleming $\mathrm{H}$. Revell.

Neimark, E. D. (1975). Intellectual development during adolescence. In F. D. Horowitz (Ed.), Review of Child Development Research (Vol. 4, pp. 541-594). Chicago: The University of Chicago Press.

Piaget, J. (1968). Six psychological studies. New York: Random House.

Piaget, J. (1970). Piaget's theory. In P. H. Mussen (Ed.), Carmichael's manual of child psychology (pp. 703-732). New York: John Wiley \& Sons.

Shepperson, V. L. (1981). Paradox, parables and change: One approach to Christian hypnotherapy. Journal of Psychology and Theology, 9, 3-11.

Sontag, L. W. \& Newberry, H. (1940). Normal variations of fetal heart rate during pregnancy. American Journal of Obstetrics and Gynecology, 40, 449-452.

Spelt, D. K. (1948). The conditioning of the human fetus in utera. Journal of Experimental Psychology, 38, 338-346.
Stein, R. H. (1981). Introduction to the parables of Jesus. Philadelphia: Westminster Press.

Thorson, W. R. (1981). The biblical insights of Michael Polanyi. Journal of the American Scientific Affiliation, $33,129-138$.

\section{AUTHORS}

FOSTER, JAMES D. Address: Department of Psychology, George Fox College, Newberg, Oregon 97132. Title: Assistant Professor of Psychology. Degrees: MA, PhD, Ohio State University. Specializations: Educational and developmental psychology.

MORAN, GLENN T. Address: George Fox College, Newberg, Oregon 97132. Title: Associate Professor. Degrees: MA, University of Colorado; EdD, University of Northern Colorado. Specializations: Math and Science Education. 


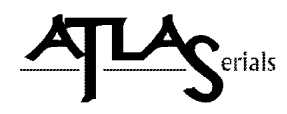

Copyright and Use:

As an ATLAS user, you may print, download, or send articles for individual use according to fair use as defined by U.S. and international copyright law and as otherwise authorized under your respective ATLAS subscriber agreement.

No content may be copied or emailed to multiple sites or publicly posted without the copyright holder(s)' express written permission. Any use, decompiling, reproduction, or distribution of this journal in excess of fair use provisions may be a violation of copyright law.

This journal is made available to you through the ATLAS collection with permission from the copyright holder(s). The copyright holder for an entire issue of a journal typically is the journal owner, who also may own the copyright in each article. However, for certain articles, the author of the article may maintain the copyright in the article. Please contact the copyright holder(s) to request permission to use an article or specific work for any use not covered by the fair use provisions of the copyright laws or covered by your respective ATLAS subscriber agreement. For information regarding the copyright holder(s), please refer to the copyright information in the journal, if available, or contact ATLA to request contact information for the copyright holder(s).

About ATLAS:

The ATLA Serials (ATLAS $®$ ) collection contains electronic versions of previously published religion and theology journals reproduced with permission. The ATLAS collection is owned and managed by the American Theological Library Association (ATLA) and received initial funding from Lilly Endowment Inc.

The design and final form of this electronic document is the property of the American Theological Library Association. 